\title{
Clinical Significance of Ki-67 Staining Index in Acoustic Neurinoma
}

\author{
Masao YoKoYAMA, Masayuki MATSUDA, Satoshi NAKASU, \\ Masayuki NAKAJIMA, and Jyoji HANDA
}

Department of Neurosurgery, Shiga University of Medical Science, Ohtsu

\begin{abstract}
The correlation between various clinical parameters and MIB-1 (Ki-67) staining indices was evaluated in 58 acoustic neurinomas. The index ranged from $0.37 \%$ to $6.61 \%$ (mean $1.70 \%$ ), and did not correlate with age, sex, or initial tumor volume. Sixteen of the 18 tumors removed subtotally or partially showed regrowth, and two showed a volume reduction. The 16 patients with regrowth were divided into two groups according to Ki-67 staining index, $<2.00 \%$ and $\geqq 2.00 \%$. These groups had a significant difference in tumor doubling time (TDT). In addition, there was a significant logarithmic correlation between Ki-67 staining index and TDT. Ki-67 staining index can be used as an index of regrowth rate in partially or subtotally removed acoustic neurinomas. Intraoperative assessment of Ki-67 staining index may be useful for better management planning as well as the estimation of prognosis.
\end{abstract}

Key words: acoustic neurinoma, growth kinetics, Ki-67 staining index, MIB-1

\section{Introduction}

Modern microsurgical techniques and intraoperative monitoring have greatly improved the operative results for acoustic neurinoma. ${ }^{7,22)}$ However, the mortality and morbidity are not zero, and the facial nerve is not always preserved.$^{8)}$ Recently, the surgical procedure for acoustic neurinoma has shifted toward less invasive surgery preserving function, so, for example, tumor attached to functionally important structures such as the facial nerve should be intentionally left to avoid functional morbidity. ${ }^{21)}$ There is also increasing interest in stereotactic radiosurgery for acoustic neurinoma, which efficiently arrests tumor growth without major complications. ${ }^{5,18,26)}$ The growth rate of acoustic neurinomas is highly variable, ${ }^{1,4,13,14,25,27)}$ so a reliable way to estimate the growth rate of acoustic neurinomas would be of great clinical value for the planning of patient management.

Study of cell kinetics has shown that the proliferative potential of brain tumors can be analyzed immunohistochemically using antibodies against deoxyribonucleic acid polymerase $\alpha$, proliferating cell nuclear antigen (PCNA), bromodeoxyuridine, or Ki-

Received February 15, 1996; Accepted May 8, 1996
67 antigen. ${ }^{2,11,12,15,19,23)}$ All these methods have inherent limitations, but MIB-1 (Ki-67) immunohistochemistry can be applied to routinely processed surgical specimens. ${ }^{3,6)}$

The present study measured the tumor doubling time (TDT) and evaluated the correlation between various clinical parameters of acoustic neurinomas and Ki-67 staining index in formalin-fixed and paraffin-embedded sections.

\section{Materials and Methods}

Sixty-seven patients, 43 females and 24 males aged 17-78 years (mean 52.2 years), with acoustic neurinomas without stigmata of neurofibromatosis were operated on between April 1979 and March 1993. Clinical charts and all available radiological studies were reviewed.

Forty of the 67 patients underwent follow-up imaging studies at more than 1 year after the first operation, with the mean follow-up period of 4.5 years (range 1.0-11.9 years). The 40 patients were divided into four groups according to the extent of removal: total removal (T), tumor was totally removed; nearly total removal (NT), a small portion of the tumor remained at operation but no residual tumor was observed in the postoperative radiological studies; sub- 
total removal (ST), more than $90 \%$ of tumor was removed; and partial removal (P), tumor was partially removed. ${ }^{21)}$

Preoperative tumor size was calculated by the method of Linsky et al., ${ }^{16)}$ based on either computed tomography (CT) or magnetic resonance (MR) imaging. Five parameters were measured: width (A), length (B), and height (C) of the extrameatal solid tumor, and diameter (X) and depth (Y) of the internal acoustic meatus. The total tumor volume was calculated as intracanalicular tumor volume $[\pi(\mathrm{X})(\mathrm{X})$ (Y)/6] plus extrameatal tumor volume [ $\left.4 \pi(\mathrm{D} / 2)^{3} / 3\right]$, where $\mathrm{D}=(\mathrm{A}+\mathrm{B}+\mathrm{C}) / 3$. Postoperative followup tumor volume was calculated by the following method, since the residual tumors usually showed irregular shape. Tumors on contiguous slices of known thickness were traced on graph papers and the areas were calculated, from which the total volume was estimated. Cystic portions were not included in the tumor volume. TDT was calculated by the formula,

$$
\mathrm{TDT}=\mathrm{t} \log 2 / \log \left(\mathrm{V}_{\mathrm{l}} / \mathrm{V}_{0}\right)
$$

where $V_{0}$ is the immediate postoperative volume $\left(\mathrm{cm}^{3}\right), \mathrm{V}_{1}$ is the volume $\left(\mathrm{cm}^{3}\right)$ at the follow-up examination, and $t$ is the follow-up period (years).

Ki-67 staining index was determined in 58 of the 67 patients. Nine patients were excluded; two patients died of postoperative complications, and seven others were inappropriate since the specimens were too small or poorly preserved. Specimens were deparaffinized and rehydrated. Intrinsic peroxidase was blocked with $3 \% \mathrm{H}_{2} \mathrm{O}_{2}$. Specimens were placed in boiled $10 \mathrm{mM}$ citrate buffer $(\mathrm{pH} \mathrm{6.0)}$ and heated three times, each for 5 minutes, at maximum power $(800 \mathrm{~W})$ in a microwave oven. $\left.{ }^{3}\right)$

\section{Immunohistochemical staining for MIB-1}

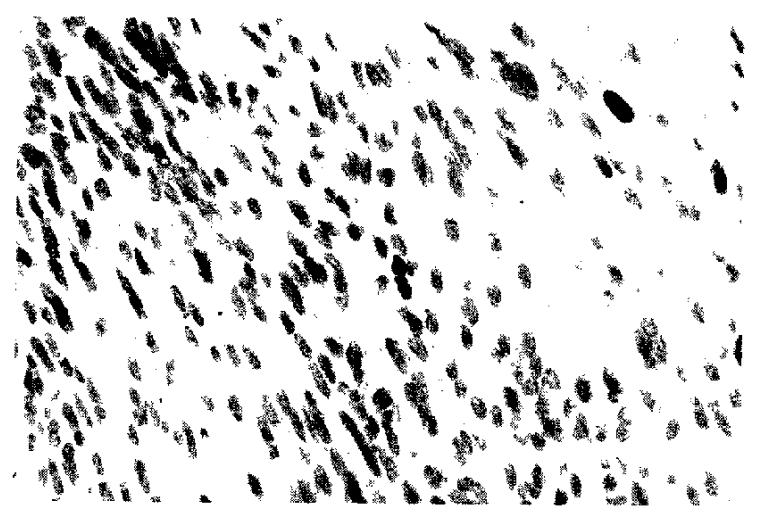

Fig. 1 Photomicrograph showing several MIB-1-positive nuclei. $\times 200$. monoclonal antibody (Immunotech, Marseille, France) $(1 / 50)$ was carried out using a LSAB kit (DAKO, Glostrup, Denmark). The Ki-67 staining indices were determined by photographing randomly selected light microscopic fields at a magnification of $\times 200$ or $\times 400$. The number of stained and unstained nuclei of tumor cells (a total of at least 2000 tumor cells for each specimen) were counted (Fig. 1). The staining index was defined as the percentage of $\mathrm{Ki}$-67-positive nuclei.

Correlations between the TDT of acoustic neurinoma, age, sex, tumor size, and $\mathrm{Ki}-67$ staining index were analyzed using the Mann-Whitney $U$ test and Pearson's correlation coefficient.

\section{Results}

The Ki-67 staining index for the 58 patients ranged from $0.37 \%$ to $6.61 \%$ (mean $1.70 \%$ ). The Ki-67 staining index did not correlate with age $(p<0.46)$ or preoperative tumor volume $(\mathrm{p}<0.72)$, and did not differ significantly between females and males (Mann-Whitney U test, $\mathrm{p}<\mathbf{0 . 6 4}$ ). The frequency of the Ki-67 staining index had a lognormal distribution (Fig. 2).

The tumor volume was measured in 38 of the 40 patients (Table 1). Two patients were excluded because of postoperative hemorrhage or poor image quality. Twenty patients were categorized in the $\mathrm{T}$ or NT group, 13 in the ST, and the remaining five in the $P$ groups. Two of the 20 patients in the $T$ and NT groups had regrowth (Table 1). Both had relatively high Ki-67 staining indices, $1.92 \%$ and $2.93 \%$. The TDT could not be estimated in these two patients, as the immediate postoperative CT scans or MR images

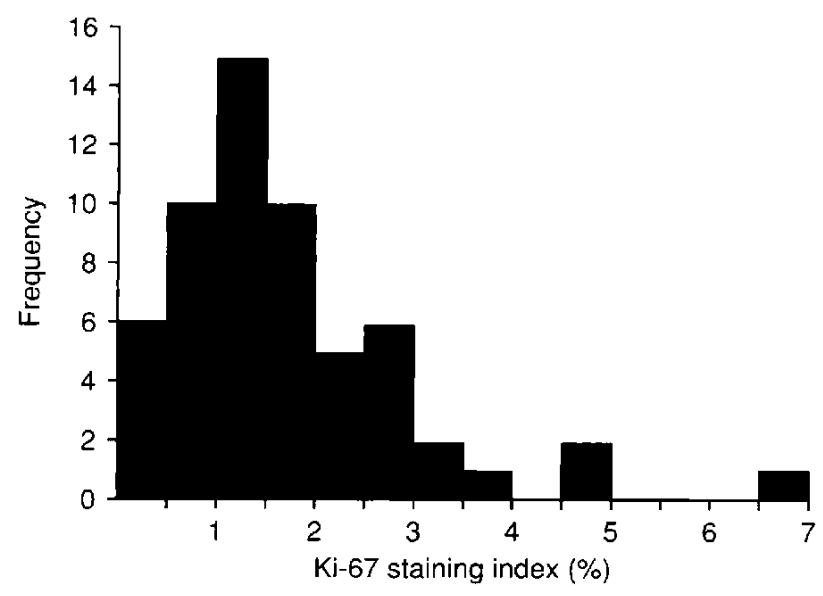

Fig. 2 Frequency distribution of Ki-67 staining index in 58 acoustic neurinomas. 
Table 1 Extent of removal and regrowth rate in 38 patients

\begin{tabular}{cccc}
\hline Operative removal & No. of cases & No. of regrowth (\%) \\
\hline T & 11 & 1 & $(9)$ \\
NT & 9 & 1 & $(11)$ \\
ST & 13 & 11 & $(85)$ \\
P & 5 & $5(100)$ \\
\hline
\end{tabular}

Table 2 Summary of 16 patients in ST and P groups with regrowth

\begin{tabular}{|c|c|c|c|c|c|c|}
\hline \multirow{2}{*}{$\begin{array}{l}\text { Case } \\
\text { No. }\end{array}$} & \multirow{2}{*}{$\begin{array}{l}\text { Age/ } \\
\text { Sex }\end{array}$} & \multicolumn{2}{|c|}{ Volume $\left(\mathrm{cm}^{3}\right)$} & \multirow{2}{*}{$\begin{array}{c}\mathrm{TDT} \\
\text { (year) }\end{array}$} & \multirow{2}{*}{$\begin{array}{c}\mathrm{t} \\
\text { (year) }\end{array}$} & \multirow{2}{*}{$\begin{array}{c}\text { Ki-67 } \\
\text { staining } \\
\text { index }(\%)\end{array}$} \\
\hline & & $v_{0}$ & $V_{1}$ & & & \\
\hline 1 & $47 / F$ & 0.15 & 0.24 & 2.22 & 1.55 & 2.24 \\
\hline 2 & $59 / \mathrm{M}$ & 2.10 & 14.30 & 0.98 & 2.70 & 3.82 \\
\hline 3 & $30 / F$ & 15.30 & 39.20 & 2.72 & 3.69 & 1.53 \\
\hline 4 & $51 / \mathrm{M}$ & 5.20 & 15.80 & 2.10 & 3.36 & 1.00 \\
\hline 5 & $74 / \mathrm{F}$ & 1.20 & 9.90 & 3.31 & 10.07 & 1.68 \\
\hline 6 & $62 / F$ & 9.73 & 22.50 & 1.22 & 1.48 & 2.42 \\
\hline 7 & $18 / F$ & 0.20 & 4.58 & 0.70 & 3.18 & 4.78 \\
\hline 8 & $50 / \mathrm{F}$ & 0.73 & 1.00 & 17.70 & 8.02 & 1.21 \\
\hline 9 & $36 / \mathrm{M}$ & 0.78 & 2.67 & 2.33 & 4.14 & 1.14 \\
\hline 10 & $65 / \mathrm{F}$ & 3.44 & 19.40 & 1.66 & 4.14 & 2.50 \\
\hline 11 & $46 / F$ & 0.51 & 0.86 & 1.98 & 1.49 & 1.16 \\
\hline 12 & $48 / F$ & 1.54 & 2.71 & 1.13 & 1.00 & 3.40 \\
\hline 13 & $34 / F$ & 1.01 & 1.60 & 8.34 & 5.54 & 1.04 \\
\hline 14 & $63 / F$ & 0.40 & 0.61 & 4.50 & 2.77 & 1.58 \\
\hline 15 & $51 / \mathrm{M}$ & 0.23 & 0.59 & 2.72 & 3.70 & 2.52 \\
\hline 16 & $63 / F$ & 0.26 & 0.37 & 6.14 & 3.01 & 0.86 \\
\hline
\end{tabular}

$t$ : follow-up period, TDT: $t \log 2 / \log \left(V_{1} / V_{0}\right), V_{0}$ : tumor volume measured on the films of immediate postoperative study, $\mathrm{V}_{1}$ : tumor volume at the followup study.

did not demonstrate the residual tumor.

Sixteen of the 18 patients in the ST and $\mathrm{P}$ groups showed regrowth and two patients had a reduction in tumor volume (Table 1). The 16 patients with regrowth were divided into two groups according to Ki-67 staining index: seven patients with a value of

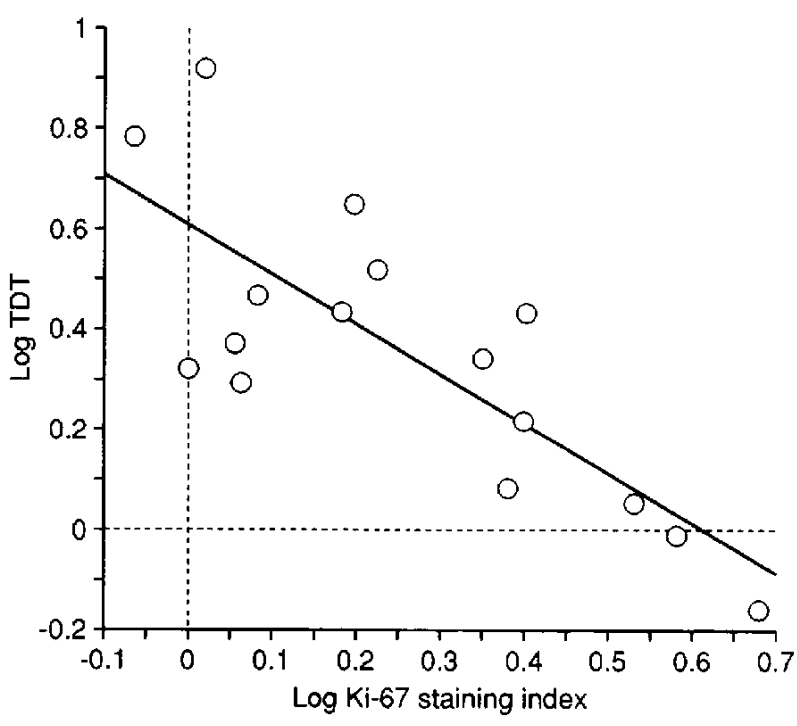

Fig. 3 Ki-67 staining indices plotted against TDT in 16 patients in ST and P groups with regrowth, showing a significant correlation $(\mathrm{Y}=$ $-0.994 X+0.614, \mathrm{r}=0.787, \mathrm{p}<0.001$ ).

$2.00 \%$ or more and nine patients with a value of less than $2.00 \%$ (Tables 2 and 3). The TDT was 1.52 years and 5.46 years, respectively. The difference in the TDT between these two groups was statistically significant (Mann-Whitney $U$ test, $p<0.01$ ). There was a significant logarithmic correlation between the Ki-67 staining index and TDT $(\mathrm{Y}=-0.994 \mathrm{X}+$ $0.614, \mathrm{r}=0.787, \mathrm{p}<0.001$ ) in these 16 tumors (Fig. $3)$.

\section{Discussion}

Most previous studies have failed to find any definitive relationship between tumor growth and various clinical factors such as length of follow-up period, patient age, or radiological or histological features. ${ }^{14,24)}$ However, histopathological factors such as hyaline degeneration, cell density, and PCNA labeling index may be a factor affecting the regrowth

Table 3 Subgroups of the ST and P patients with regrowth according to Ki-67 staining index

\begin{tabular}{|c|c|c|c|c|c|c|}
\hline \multirow{2}{*}{$\underset{(\%)}{\mathrm{Ki}-67 \underset{\text { staining index }}{(\%)}}$} & \multirow{2}{*}{$\begin{array}{l}\text { No. of } \\
\text { patients }\end{array}$} & \multirow{2}{*}{$\begin{array}{c}\text { Mean age } \\
\text { (year) }\end{array}$} & \multicolumn{2}{|c|}{ Sex } & \multirow{2}{*}{$\begin{array}{l}\text { Follow-up period } \\
\text { (year)* }\end{array}$} & \multirow{2}{*}{ TDT (year)* } \\
\hline & & & $\mathrm{F}$ & $\mathbf{M}$ & & \\
\hline$<2.00$ & 9 & 49.7 & 7 & 2 & $4.68 \pm 2.75$ & $5.46 \pm 5.06$ \\
\hline$\geqq 2.00$ & 7 & 50.0 & 5 & 2 & $2.54 \pm 1.21$ & $1.52 \pm 0.73$ \\
\hline
\end{tabular}

*Values are expressed as mean $\pm \mathrm{SD}$. 
rate. $^{10)}$

The mean $\mathrm{Ki}-67$ staining index of acoustic neurinoma was $0.2-1.3 \%$ in several small series. ${ }^{2,11,12,19,23)}$ The present study showed a slightly higher value of $1.70 \%$. Lesser et al. ${ }^{15)}$ found that acoustic tumors can be divided into two groups with large differences in growth rate; the $\mathrm{Ki}-67$ staining index in one group was five times higher than in the other. Our study showed similar results (Table 3), and the frequency distribution of $\mathrm{Ki}-67$ staining indices was lognormal (Fig. 2).

In this study, the patients in the ST and P groups with residual tumor naturally showed a high rate of regrowth, whereas only two of 20 patients in the $T$ and NT groups had regrowth. Tani et al. ${ }^{21)}$ also reported that none of the $\mathrm{T}$ group developed regrowth and that only two of 26 patients in the NT group showed regrowth. A longer follow-up period is necessary before concluding whether tumors in $\mathrm{T}$ and NT groups rarely regrow or not, since neurinomas generally have a low proliferation potential. We also found decreased tumor size during the followup period in two of 18 cases in the ST and $\mathrm{P}$ groups. Such regression of the remaining tumor has been previously reported, ${ }^{1,9,10,14)}$ and is probably due to ischemia of the remaining tumor tissue secondary to operative manipulation of the feeding arteries. ${ }^{21)}$

The average growth rate of acoustic neurinomas may be low in the elderly, ${ }^{17)}$ but we could not find any significant correlation between age and TDT. Therefore, our results do not support Silverstein $e t$ $a l .{ }^{20)}$ who advocated a conservative approach for all acoustic neurinomas in the elderly.

Most previous studies on the growth rate of acoustic neurinomas described the increase in the maximum diameter, ${ }^{1,4,10,25)}$ and only a few studies employed the change in the tumor volume as an indicator of growth rate or TDT. ${ }^{13,14)}$ Our results showed a good logarithmic correlation between the Ki-67 staining index and TDT of acoustic neurinoma (Fig. 3). In addition, the difference in TDT between patient groups with $<2.00 \%$ and $\geqq 2.00 \% \mathrm{Ki}-67$ staining index was statistically significant (Table 3 ). Although proliferation or cell loss rates of the tumor might be modified by operative procedures, our results show that the $\mathrm{Ki}-67$ staining index is useful as an index of regrowth rate in partially or subtotally removed acoustic neurinomas. Intraoperative assessment of the Ki-67 staining index using frozen sections may allow better management planning as well as the estimation of prognosis.

\section{References}

1) Bederson JB, von Ammon $\mathrm{K}$, Wichmann WW, Yasargil MG: Conservative treatment of patients with acoustic tumors. Neurosurgery 28: 646-651, 1991

2) Burger PC, Shibata $T$, Kleihues $P$ : The use of the monoclonal antibody $\mathrm{Ki}-67$ in the identification of proliferating cells: Application to surgical neuropathology. Am J Surg Pathol 10: 611-617, 1986

3) Cattoretti G, Becker MH, Key G, Duchrow $M$, Schlüter C, Galle J, Gerdes J: Monoclonal antibodies against recombinant parts of the Ki-67 antigen (MIB 1 and MIB 3) detect proliferating cells in microwaveprocessed formalin-fixed paraffin sections. $J$ Pathol 168: 357-363, 1992

4) Clark WC, Moretz WH, Acker JD, Gardner LG, Eggers F, Robertson JH: Nonsurgical management of small and intracanalicular acoustic tumors. Neurosurgery 16: 801-803, 1985

5) Flickinger JC, Lunsford LD, Coffey RJ, Linskey ME, Bissonette DJ, Maits AH, Kondziolka D: Radiosurgery of acoustic neurinomas. Cancer 67: 345-353, 1991

6) Gerdes J, Lemke H, Baisch H, Wacker HH, Schwab $U$, Stein H: Cell cycle analysis of a cell proliferationassociated human nuclear antigen defined by the monoclonal antibody Ki-67. J Immunol 133: 17101715,1984

7) Haines SJ, Levine SC: Intracanalicular acoustic neuroma: Early surgery for preservation of hearing. $J$ Neurosurg 79: 515-520, 1993

8) Harner SG, Ebersold MJ: Management of acoustic neuromas, 1978-1983. I Neurosurg 63: 175-179, 1985

9) Kameyama S, Tanaka R, Honda $Y$, Hasegawa A, Yamazaki H, Kawaguchi T: The long-term growth rate of residual acoustic neurinomas. Acta Neurochir (Wien) 129: 127-130, 1994

10) Kawamoto $Y$, Uozumi T, Kiya K, Fujioka $Y$, Kurisu $\mathrm{K}$, Kawamoto $\mathrm{K}$, Sugiyama K: Clinicopathologic growth factors of acoustic neuromas. Surg Neurol 43: 546-552, 1995

11) Khoshyomn S, Maier $H$, Morimura $T$, Kitz K, Budka $\mathrm{H}$ : Immunostaining for proliferating cell nuclear antigen: Its role in determination of proliferation in routinely processed human brain tumor specimens. Acta Neuropathol (Berl) 86: 582-589, 1993

12) Kunishio K, Mishima N, Matsuhisa $T$, Tsuno $K$, Matsumi N, Satoh T, Matsumoto K, Furuta T, Nishimoto A, Shiraishi T: Immunohistochemical demonstration of DNA polymerase $\alpha$ in human brain-tumor cells. $J$ Neurosurg 72: 268-272, 1990

13) Kusakari J, Kobayashi $T$, Inamura N, Shibuya M, Ohdaira $H$, Kawase T, Takeyama M, Kikuchi T, Takasaka T, Kawamoto K: Studies on the growth rate of acoustic tumor. Nippon Jibiinkoka Gakkai Kaiho 90: 324-328, 1987 (in Japanese) 
14) Laasonen EM, Troupp H: Volume growth rate of acoustic neurinomas. Neuroradiology 28: 203-207, 1986

15) Lesser THJ, Janzer RC, Kleihues P, Fisch U: Clinical growth rate of acoustic schwannomas. Correlation with the growth fraction as defined by the monoclonal antibody Ki-67. Skull Base Surgery 1: $11-15,1991$

16) Linsky ME, Lunsford LD, Flickinger JC: Neuroimaging of acoustic nerve sheath tumors after stereotaxic radiosurgery. AJNR Am J Neuroradiol 12: 11651175,1991

17) Nedzelski JM, Canter RJ, Kassel EE, Rowed DW, Tator $\mathrm{CH}$ : Is no treatment good treatment in the management of acoustic neurinomas in the elderly? Laryngoscope 96: 825-829, 1986

18) Norén G, Greitz D, Hirsch A, Lax I: Gamma knife surgery in acoustic tumors. Acta Neurochir Suppl (Wien) 58: 104-107, 1993

19) Shibata T, Burger PC, Paul K: Cell kinetics of human meningiomas and neurinomas: Ki-67 PAP stain. No Shinkei Geka 16: 939-944, 1988 (in Japanese)

20) Silverstein $H$, McDaniel A, Norrell $H$, Wazen $J$ : Conservative management of acoustic neuroma in the elderly patient. Laryngoscope 95: 766-770, 1985

21) Tani S, Shinoda S, Koyama T, Tanaka H, Hashimoto T, Nakamura N, Abe T: Evaluation of the postoperative regrowth of the acoustic neurinomas. No Shinkei Geka 21: 909-913, 1993 (in Japanese)

22) Tatagiba $M$, Samii $M$, Matthies $C$, El Azm $M$, Schönmayr $\mathbf{R}$ : The significance for postoperative hearing of preserving the labyrinth in acoustic neurinoma surgery. $J$ Neurosurg 77: 677-684, 1992

23) Tsanaclis AM, Robert F, Michaud J, Brem S: The cycling pool of cells within human brain tumors: In situ cytokinetics using the monoclonal antibody Ki-67. Can J Neurol Sci 18: 12-17, 1991

24) Valvassori GE, Shannon M: Natural history of acoustic neuromas. Skull Base Surgery 1: 165-167, 1991

25) Wazen J, Silverstein H, Norrell H, Besse B: Preoperative and postoperative growth rates in acoustic neuromas documented with $\mathrm{CT}$ scanning. Otolaryngol Head Neck Surg 93: 151-155, 1985

26) Yamamoto M, Norén G: Stereotactic radiosurgery in acoustic neurinomas. No Shinkei Geka 18: 11011106,1990 (in Japanese)

27) Zöllner $C$, Bockenheimer $S$ : The growth rate of acoustic neuromas: A report of three cases. Arch Otorhinolaryngol 241: 259-264, 1985

Address reprint requests to: M. Yokoyama, M.D., Department of Neurosurgery, Shiga University of Medical Science, Tsukinowa-cho, Seta, Ohtsu 520-21, Japan.

\section{Commentary}

The authors have presented interesting data on the regrowth rate and MIB-1 (Ki-67) staining indices for acoustic neurinomas. There was a correlation noted between the doubling time and the Ki-67 staining index, using $2 \%$ of cells staining as a dividing point. They suggest that intraoperative staining for Ki-67 index might be of benefit during the resection.

Surgical intervention has in fact become more aggressive in some respects in that we are now operating earlier in an attempt to preserve hearing while obtaining complete tumor removal." Microsurgical excision of acoustic schwannomas has progressed to where we can now resect almost all $(99 \%)$ of these tumors completely without great risk to the facial nerve. If this can be done, I see no reason to leave residual tumor. The only situations where we intentionally leave tumor are: 1) in patients where the last scrap of tumor is too adherent to the facial nerve to remove without potential injury to the nerve, 2) in those patients who absolutely refuse to allow dissection along the facial nerve for fear of paresis, or 3) where an aggressive intracapsular removal is done without dissection of the facial nerve to expedite surgery in the elderly. Intraoperative staining for Ki-67 might not alter those decisions.

Nevertheless, this information is interesting in learning more about the natural history of these tumors. As there was no correlation between Ki-67 index and age, the notion that tumors in older patients grow more slowly may come into question. However, only one patient in this series was over the age of 65 .

\section{Reference}

1) Post $K D$, Eisenberg $M$, Catalano PJ: Hearing preservation in vestibular schwannoma surgery: What factors influence outcome. / Neurosurg 83: 191-196, 1995

$$
\begin{array}{r}
\text { Kalmon D. PoST, M.D. } \\
\text { Neurosurgery } \\
\text { Mount Sinai Medical Center } \\
\text { New York, U.S.A. }
\end{array}
$$

Until recently, it was difficult to predict the regrowth rate and prognosis of acoustic neurinomas. Now, the antibody to $\mathrm{Ki}-67$ antigen, MIB-1, is available routinely for application to formalin-fixed, paraffin-embedded specimen to determine the proliferation potential of various CNS tumors including acoustic neurinomas. Some studies using Ki-67 staining index (SI) demonstrated that acoustic neurinomas have several distinct growth rates. ${ }^{1-3)}$ The authors state 
that $\mathrm{Ki}-67 \mathrm{SI}$ is significantly related to tumor doubling time (TDT) and a $\mathrm{Ki}-67 \mathrm{SI}$ of $\geqq 2 \%$ is associated with shorter TDT. The cutoff value of $2 \%$ appears to be tentative, because this study was performed on a relatively small number of cases. A much larger and longer-term follow-up study may provide more valid information to evaluate the biological behavior of acoustic neurinomas.

\section{References}

1) Charabi $S$, Engel $P$, Jacobsen $G K$, Tos $M$, Thomsen J: Growth rate of acoustic neuroma expressed by Ki-67 nuclear antigen versus symptom duration. Ann Otol
Rhinol Laryngol 102: 805-809, 1993

2) Lesser THJ, Janzer RC, Kleihues P, Fisch U: Clinical growth rate of acoustic schwannomas: correlation with the growth fraction as defined by the monoclonal antibody Ki-67. Skull Base Surgery 1: 1115,1991

3) Szeremeta W, Monsell EM, Rock JP, Caccamo DV: Proliferation indices of vestibular schwannomas by $\mathrm{Ki}$ 67 and proliferating cell nuclear antigen. Am / Otol 16: 616-619, 1995

Junkoh YaMASHITA, M.D. Department of Neurosurgery Kanazawa University School of Medicine Kanazawa, Japan 